\title{
Editorial: For effective strategy pre-empt resistance
}

The high failure rate in new product introductions is well known. Not as well acknowledged is the high failure rate of brand ad campaigns. After 30 years in research and continuous tracking of hundreds of ad campaigns and numerous product introductions, the writer is convinced that a key reason for the high failure rate in both is that too many ad campaigns, like too many product introductions, combatively try to change existing behaviour and attitudes. ${ }^{1}$

Yet the evidence has been around for decades that this is rarely effective. The most effective strategy taps into the psychology of the people being aimed at and attempts to induce change in the behaviour while avoiding confrontation with pre-existing attitudes or dispositions. It seems that over the years this important lesson has lost some of its salience in marketing as people have become less conscious of it.

There is no better way to illustrate its potency than with the following anecdote of an astute school principal receiving complaints from the cleaner of the school's washrooms about the persistent lipstick on the mirrors. The girls had taken to pressing their lips to the mirror each day and were urged to refrain - a communication strategy that was not working. So the principal gathered the girls in the washroom to explain how hard it was to remove the lipstick and asked the cleaner to demonstrate. Taking a wide paintbrush, the cleaner dipped it liberally in the toilet bowl and proceeded to 'paint' the mirror with the moistened brush. From then on, the school experienced no further problems with lipstick on mirrors!

This school principal clearly recognised the difference between combative strategies and more subtle strategies that do not invite resistance but tap into people's dispositions. New product introduction strategy, as well as communication strategy, works best when it adopts this principle. Why do dishwashing detergents have suds? It is because, back in the days when dishwashing detergent was first invented, manufacturers had to put suds into the product to get around a confrontation with pre-existing attitudes.

Suds were not in the original product formulation and are not necessary for it to work. However, in the era before detergent, people washed dishes in soapy water in the sink and it was the lack of suds on the top of the water that told them when things were not working and when they needed to add more soap. Without foam, detergent was not seen to be working. It clashed with what was well established in buyers' minds - namely that sudsing equals 'working' and lack of suds indicated 'not working'. When manufacturers added suds to detergents, they walked around such confrontation, enabling them to formulate an effective communication strategy. The rest, as they say, is history.

In the same way, manufacturers of packaged cake mixes often require buyers to add eggs to the prepackaged mix. These were included in the recipe 
after research discovered that people felt dissatisfaction with making something as indulgent and nurturing as a cake when they had no personal input.

It seems people need a reminder that the direct combative approach of confronting attitudes head on is usually a very costly way to go. The combative approach may perhaps eventually succeed, but only if it can be kept going long enough. It usually requires a long, hard and very costly battle over many years before the resistance is eventually broken down. Few companies can afford that and today's shareholders are notoriously intolerant of companies which offer long-term promises at the expense of current returns.

It is not a revelation that people's minds tend to reject that which is not consistent with what they know, expect, or want to do. It is a notion that has been around for a long time, yet it is surprising how often it seems to get overlooked. Why? The author's experience is that there are two key factors underlying it:

- insufficient or inadequate research that fails to flag in advance the impending attitude clash

— insufficient attention or importance accorded to the research finding so as to set it up clearly in terms of a creative challenge.

\section{CREATIVE CHALLENGE}

When research flags an impending clash and enough importance is accorded to it, only then is it likely to be set up as a creative challenge to be addressed. Only then is it likely to be 'briefed in' and receive the necessary amount of creative attention. A crea- tive solution will rarely just emerge naturally from research. Research is important, but it alone is unlikely to suggest a solution.

The following illustration is a hypothetical example. A brand of canned fish called Fine-C Foods has been long established globally as a high-quality brand and uses the slogan 'It's the fish that Fine-C rejects that makes Fine-C the best'. ${ }^{2}$ The quality image of the brand is paramount in this brand's positioning and it is about to enter a new but related category with jars of fish-paste spread. Consistent with its positioning, it will market quality fish paste and compete with the existing brands, all of which are rather poor quality. 'Fine-C - superior quality fish paste' has been designed to work in harmony with the preexisting, quality image this brand is known for. So far so good.

A real limitation lurks below the surface, however, if there is a widespread belief among consumers (and indeed there is among many people), that 'fish paste' is made of leftovers, after all the good parts of the fish have been used for something else. Research might note this observation but there is an ever-present danger of it getting lost in the clutter of all the many other research observations. The amount of attention that is flagged here by the research will be crucial. Someone has to point out the implication of this; that 'Fine-C superior quality fish paste' is likely to translate unconsciously in consumers' minds as 'Fine-C superior quality leftovers'.

Management needs to know clearly that the new product is facing a clash - that there is an impending inconsistency with the desired image, and they 
are faced with the unenviable task of trying to convince people that Fine-C fish paste is not made from leftovers but from the best-quality fish.

Exercising the creative process on the problem at least gives a chance of coming up with a solution. For example, in this case someone might come up with a strategy of renaming the product and marketing it under the name 'Fish Pate'. Pate has quite different associations that are more consistent with the quality positioning of the Fine-C brand. A positioning line such as 'Fine-C Fish Pate — the quality alternative to fish paste' is more likely to succeed than a strategy of directly confronting entrenched attitudes and beliefs about the 'leftovers' make-up of fish paste.

Note the importance of the flagging by the research, the 'briefing in' for a solution and the creativity that is involved in the solution. Research that notes a belief that fish paste is made from leftovers is one thing. Recognising its importance and then 'briefing it in' for a creative solution is another. All too often, one or more of the parts of this process just does not seem to happen.

Gaps in the same process also lead to ad campaigns for existing brands that confront rather than tap into the buyer's predispositions. At times, descriptive reporting of focus groups can unintentionally 'bury' important attitudes and beliefs. Instead of flagging their 'clash propensity' they get lost in the comprehensive clutter of research findings. Similarly, comments that have important potential for communication strategy leverage can also get 'buried'. Research observations like 'I hate that Microsoft ... it's too big' or 'AOL regard me as an account number rather than a customer' may lie fallow unless sufficient attention is flagged to them so that the necessary creativity is applied and the strategy implications teased out. It demands interpretive rather than merely descriptive reporting by researchers.

Avis teased out the strategy implications of comments such as these many years ago and executed them in the famous 'Avis - we try harder' campaign. It worked because it capitalised on the widespread belief that monopolies and big companies tend to become complacent, while those that are still trying to get to the top will try harder. When an ad is cognitively consistent with what is already known and fits with people's predispositions, it hits the ground running with traction and preestablished momentum. By contrast, the combative approach often takes considerable time to overcome resistance before it can hope to achieve any momentum.

\section{RESISTANCE}

Adopting a non-combative approach does not mean giving up on trying to influence people. It means using research and creativity to minimise resistance. The more overt and combative the persuasion attempt, the more it tends to invite mental resistance. On the other hand, the more subtle it is, and the more it fits with existing mindsets, the less likely it is to invite resistance. In the intensity of planning and implementing new product launches and new campaign launches people seem to have a tendency to lose sight of this.

People are more likely to embrace change if they feel they have reached a conclusion 'by themselves'. With creativity focused on the problem, it is 
usually possible to rejig communications so as at least to minimise inviting resistance. Some of these points are discussed in a recent book by the writer. ${ }^{3}$ One way, for example, is to avoid addressing directly the people one wants to convert. They are the ones most likely to resist. If one lets them hear the communication as 'bystanders' the effect is different. When people hear something as a bystander, it tends not to invite the same degree of resistance. $^{4}$

For example, if Toyota wants to convince truck buyers that their trucks are really tough and long lasting, they can take the head-on approach and assert it directly in a campaign aimed at those who currently drive other brands. Or they can do what Toyota did in a great campaign some years ago in the USA. A curious campaign, it featured vignettes of actual Toyota truck owners describing, on screen, exactly where they were and what they were doing when their Toyota truck clocked up $100,000,200,000$ or 300,000 miles. It invited the Toyota truck owner to telephone a toll-free number and 'tell us where you were and what you were doing when your Toyota truck turned 100,000, 200,000 or 300,000 miles'.

It was an inventive campaign that could not help but reinforce the repeat buying of existing owners of Toyota trucks by reminding them of the durability of their truck and making them proud of the huge number of miles it had endured. Moreover, and just as importantly, it gets across the message to the 'bystanders', those driving or contemplating buying other brands, that these Toyotas must be very, very durable machines indeed. When people are exposed as 'bystanders', an ad can communicate just the same but it is much less likely to provoke counterarguing. 'Bystanders' do not look to prove or disprove anything when the communication is not addressed to them.

\section{CONCLUSION}

Companies can rarely afford protracted efforts to engage entrenched attitudes by confronting them directly. It seems that over the years people have forgotten some of the lessons that were learned earlier. Effective strategy means finding and utilising something that already exists in people's minds, that is consistent with them buying or rebuying the brand, and then exercising creativity based on that to position the brand in line with it. The most effective strategies tap into the psychology of the people they are trying to influence and recognise, as the school principal did, that it is better to preempt and avoid resistance than to waste resources trying to combat it.

\section{Dr Max Sutherland Editorial Board}

\section{References}

(1) Sutherland, M. and Sylvester, A. K. (2000) 'Advertising and the Mind of the Consumer: What Works, What Doesn't and Why', Kogan Page, London.

(2) This is a positioning line used very successfully in Australia for the brand John West.

(3) Sutherland and Sylvester, ref. 1 above.

(4) See, for example, Walster, E. and Festinger, L. (1962) "The effectiveness of "overheard" persuasive communications', Journal of Abnormal and Social Psychology, Vol. 65, pp. 395-402. 